\title{
Controle de qualidade interlaboratorial em imuno-histoquímica: citoceratinas e receptor de estrógeno como modelos
}

\author{
Interlaboratorial quality-control in immunohistochemistry: cytokeratins and estrogen receptors as models
}

Venâncio Avancini Ferreira Alves'; Luciana de Oliveira Leandro2; José Vassallo30; Emílio Marcelo Pereira4; Cristina Takami Kanamura ; Alda Wakamatsu'; Raimunda Telma de Macedo Santos5; Suely Nonogakis; laboratórios do Clube de IHQ*

\begin{tabular}{l|l}
\multicolumn{1}{c|}{ Unitermos } & resumo \\
Imuno-histoquimica & $\begin{array}{l}\text { Introdução: O grande incremento do uso da imuno-histoquímica (IHQ) em numerosos laboratórios de } \\
\text { anatomia patológica amplia o poder de resolução diagnóstica, mas traz certo grau de heterogeneidade } \\
\text { Citoceratinas }\end{array}$ \\
Receptor de estrógeno & $\begin{array}{l}\text { de procedimentos e resultados. Seguindo recentes propostas da literatura internacional, participantes } \\
\text { do Clube de IHQ da Sociedade Brasileira de Patologia desenvolvem ações de controle de qualidade, } \\
\text { aplicando protocolos de sua rotina à pesquisa de antígenos que sirvam como indicadores de qualidade } \\
\text { da reação. Material e método: Um total de dez laboratórios participou das duas etapas deste estudo, } \\
\text { cujos marcadores foram pancitoceratinas e receptores de estrógeno. Com lâminas controle recebidas } \\
\text { dos laboratórios, cada participante efetuou a técnica de IHQ conforme sua prática diária, retornando } \\
\text { as lâminas juntamente com o formulário de procedimento. A avaliação semiquantificada de } 0 \text { a } 4 \text { da } \\
\text { intensidade da reação específica e de } 0 \text { a } 3 \text { da coloração de fundo e da qualidade da técnica histológica } \\
\text { foram atribuídas individual e sigilosamente durante a projeção em data show em reunião do Clube de } \\
\text { IHQ, gerando um escore final. Resultados e discussão: As variações na imunocoloração de citocerati- } \\
\text { nas e receptor de estrógeno não comprometeram sua detecção nas lâminas preparadas nos diversos } \\
\text { laboratórios. Tais variações associaram-se à diversidade de sistemas de recuperação antigênica e de } \\
\text { amplificação, resultando ora em imunopositividade menos intensa, ora em maior fundo. Outros estudos } \\
\text { devem abordar questões de interpretação, incluindo-se critérios para semiquantificação. }\end{array}$
\end{tabular}

abstract

Background: The expansion of the use of immunohistochemistry (IHC) in numerous laboratories extends the power of diagnostic resolution, but may impart heterogeneity in procedures and results. Following recent international proposals, participants of the Club of IHC of the Brazilian Society of Pathology developed actions of quality control applying routine protocols for detection of some of the most relevant antigens as quality probes. Objectives: Ten laboratories participated on the present study on keratins and estrogen receptors. Material and method: On control-slides sent from each laboratory, each participant performed IHC reaction according to his daily practice, returning the slides with the filled procedure form. The evaluation of the intensity of the specific reaction and back-ground was performed individually during data show projection in a meeting of the Club of $I H C$, yielding a final score of performance. Discussion and conclusion: The methodology adopted was found useful to ascribe the performance to the heterogeneous systems of antigenic retrieval and amplification, leading to the identification of moderate variation in intensity of immunoreaction and in back-ground, but not compromising the antigen detection in any of these laboratories. Other studies must approach interpretative questions, including semi-quantitation and cut-offs.

\section{key words}

Immunohistochemistry

Quality control

Cytokeratins

Estrogen receptor

\footnotetext{
1. Médico patologista do Instituto Adolfo Lutz; professor-associado do Departamento de Patologia da Faculdade de Medicina da Universidade de São Paulo (FMUSP).

2. Bióloga; mestranda da Coordenação dos Institutos de Pesquisa.

3. Professor-associado do Departamento de Anatomia Patológica da Faculdade de Ciências Médicas da Universidade Estadual de Campinas (FCM/Unicamp).

4. Médico patologista do Laboratório Salomão e Zoppi.

5. Pesquisadoras cientificas do Instituto Adolfo Lutz.

*DAP/Hospital das Clínicas da Faculdade de Medicina da Universidade de São Paulo (HCFMUSP) - dra. Sheila A. C. Siqueira; Laboratório Hugo Brandão s/C - dra. Laura S. B. Vianna; Unicamp/ Laboratórios de Aplicação em Epidemiologia (Lape)/Centro de Atenção Integral à Saúde da Mulher (CAISM) e Multipat - dr. José Vassallo; Laboratório IHQ do Instituto Adolfo Lutze Cicap dr. Venâncio A. F. Alves; Salomão e Zoppi S/C - dr. Emílio M. Pereira; Hospital AC Camargo - dra. Maria Betânia M. Araúijo; Instituto Nacional do Câncer (INCa) - dr. Sérgio O. Romano; CIP - Hospital Beneficência Portuguesa - dr. Roberto P. Paes.
} 


\section{Introdução}

A detecção imuno-histoquímica (IHQ) de painéis de antígenos para diferentes tipos de tumores tem aumentado a precisão do diagnóstico histopatológico e, muitas vezes, tem permitido análise do prognóstico de diversos tipos de neoplasia ${ }^{(17,28,31)}$.

A seleção do método mais adequado é uma das grandes responsabilidades do patologista, visando à maior reprodutibilidade dos resultados por meio de procedimentos mais padronizados e, sempre que possível, tornando mais simples as reações. Isto requer conhecimento, experiência e atenção continuada de toda a equipe(2).

A introdução da imuno-histoquímica acarretou grandes avanços ao diagnóstico histopatológico, motivando o uso cada vez mais amplo, o que pode trazer certo grau de heterogeneidade de procedimentos e resultados.

Desde janeiro de 1984 e, de modo mais organizado, a partir de 1994, uma equipe de vários laboratórios de patologia participa ativamente de reuniões mensais do chamado Clube de IHQ, da Sociedade Brasileira de Patologia (SBP), com o intuito de promover ações para aprimoramento da qualidade, com apresentação de casos, discussões técnico-científicas, trabalhos em andamento e, atualmente, com a implantação de um programa interlaboratorial de aprimoramento da qualidade.

Entre as propostas para sistemas de controle de qualidade recentemente expostas na literatu$\mathrm{ra}^{(3,6,14,17,19,21,25,26,31)}$ destaca-se a distribuição de amostras para os laboratórios participantes efetuarem, segundo os protocolos aplicados em sua rotina diagnóstica, a pesquisa de alguns antígenos que sirvam com indicadores de qualidade da reação.

Na prática diagnóstica atual, o uso das citoceratinas como marcador de padrão epitelial é de grande valia em tumores morfologicamente indiferenciados ${ }^{(5,20)}$.

O receptor de estrógeno é uma proteína nuclear responsável pela mediação dos efeitos do estrógeno no epitélio mamário. Além de representar um fator preditivo à resposta terapêutica, sua imunoexpressão tem correlação com o curso clínico dos carcinomas de mama(27).

O presente estudo apresenta a estratégia de trabaIho, os protocolos de procedimento e a sistemática de avaliação do padrão de reação obtido nos laboratórios inscritos no Programa Piloto de Controle de Qualidade Interlaboratorial (PPCQIL), selecionando como indicador de qualidade a imunodetecção de pancitoceratinas e receptor de estrógeno.

\section{Material e método}

Dez laboratórios participaram deste estudo, sendo nove na primeira etapa, cujo marcador foi a detecção de pancitoceratinas, que teve 81 lâminas avaliadas. Na segunda etapa, o marcador receptor de estrógeno foi analisado por sete laboratórios, compondo um total de 49 lâminas avaliadas. Seis laboratórios participaram das duas etapas, três somente da primeira e um somente da segunda.

Os laboratórios voluntariamente inscritos no PPCQIL da SBP enviaram uma lista com seus anticorpos mais utilizados, sendo, a partir destes dados, selecionados como indicadores de qualidade os marcadores citoceratinas e receptor de estrógeno.

O formulário para as análises, discutido nas reuniões do clube, incluiu os seguintes informes: fixador, adesivo utilizado nas lâminas, navalha, sistema de recuperação antigênica, especificações dos anticorpos primário e secundário e método de amplificação (clone, diluição, tempo e temperatura de incubação), cromógeno e contracoloração.

Fluxo de procedimentos:

- cada laboratório providenciou o preparo de lâminas com secções histológicas a partir do bloco de parafina utilizado rotineiramente como controle;

- duas pessoas centralizaram o recebimento e a codificação das lâminas (código diferente em cada experimento), providenciando a distribuição para todos os laboratórios;

- as lâminas foram submetidas à técnica de imuno-histoquímica para pesquisa do antígeno conforme a rotina de cada laboratório;

- devolução das lâminas coradas junto com um formulário informativo de seu protocolo de procedimento.

Assim que a equipe organizadora recebeu todas as lâminas, codificando-as segundo o laboratório de origem e aquele que realizou o teste, elas foram projetadas em data show, em uma reunião do Clube de IHQ. Para reduzir a variação da análise interobservadores, os critérios foram discutidos conjuntamente e a pontuação, individual e sigilosa, foi atribuída simultaneamente durante a projeção, baseando-se, portanto, nos mesmos campos de observação.

Os critérios avaliados foram:

- reatividade específica para o antígeno, semiquantificada de 0 (= ausente) a 4 (= excelente);

- qualidade de técnica histológica, incluindo, entre outros, aspectos relacionados a corte, descolamento e contracoloração, semiquantificada de 0 (= insatisfatório) a 3 (= excelente); 
- coloração de fundo inespecífico, semiquantificada de 0 (= ausente) a 3 (= acentuado).

Todas as notas atribuídas foram submetidas à análise para a obtenção de escores médios de cada laboratório e consideradas de acordo com os índices abaixo:

- reatividade <2: definido como insatisfatório;

- $\quad 2$ 2: definido como satisfatório;

- coloração de fundo > 1: definido como insatisfatório;

- $\leq 1$ : definido como satisfatório;

- técnica histológica $\leq 1$ : definido como insatisfatório;

- > 1: definido como satisfatório.

\section{Resultados}

A análise inicial dos formulários preenchidos pelos laboratórios está exposta nas Tabelas 1 e 2, destacando-se as seguintes informações:

- todos os laboratórios utilizaram a formalina como método de fixação das amostras;

- nove laboratórios utilizaram navalhas descartáveis;

- o adesivo aplicado em nove laboratórios foi o silano, sendo o uso de polilisina relatado por um laboratório;

- o sistema de recuperação antigênica usado por todos os laboratórios na detecção do receptor de estrógeno foi a incubação com solução de citrato de sódio $0,01 \mathrm{M}$, pH 6, em câmara quente, variando a preferência entre o microondas, a panela de pressão e a panela a vapor. O mesmo ocorreu na detecção de citoceratinas, com exceção de um laboratório, que, para este antígeno, tem padronizado a digestão enzimática com tripsina.

Todos os laboratórios participantes utilizaram a solução de anticorpos AE1+AE3 como anticitoceratina. As diluições variaram de 1:100 a 1:1.000 e o tempo de incubação foi de 18 horas (overnight) a $4^{\circ} \mathrm{C}$ em todos os laboratórios. Para este marcador, seis laboratórios adotaram o sistema streptavidina-biotina-peroxidase (StreptABC) como método de amplificação, com diluições variando de 1:100 a 1:300, e dois laboratórios adotaram o LSAB pré-diluído, com tempo de incubação de 30 a 60 minutos, à temperatura ambiente ou a $37^{\circ} \mathrm{C}$.

Para a detecção do receptor de estrógeno (RE), três dos laboratórios participantes utilizaram o clone $6 \mathrm{~F} 11$ como anti-RE, com diluições de 1:40 e 1:50. Os demais usaram o clone 1D5, com diluições de 1:50 a 1:2.000. O tempo de incubação variou de 30 minutos a $37^{\circ} \mathrm{C}$ até 18 horas a $4^{\circ} \mathrm{C}$. Quatro laboratórios utilizaram o sistema StreptABC como método de amplificação, com diluições de 1:100 a 1:300; dois adotaram o LSAB pré-diluído; e um usou o método Envision-peroxidase, com tempos de incubação variando de 20 minutos à temperatura ambiente a 1 hora a $37^{\circ} \mathrm{C}$.

Todos os laboratórios utilizaram soluções de peróxido de hidrogênio e diamino benzidina para revelação da reação e da contracoloração com hematoxilina, seguindo-se a convencional montagem em lamínula.

O estudo das lâminas de citoceratinas está apresentado na Figura 1 e revelou que, de modo genérico, as reações apresentadas foram consideradas satisfatórias. A reatividade das estruturas epiteliais para citoceratinas teve escores médios de 2,86 (mínimo: 2,36; máximo: 3,37; mediana: 2,86). Índice superior a 3 foi obtido por três laboratórios (Figura $2 A)$, enquanto dois laboratórios apresentaram escore inferior a 2,5 neste critério (Figuras 2B, 2C e 2D).

A presença de coloração inespecífica de fundo teve escores médios de 0,58 (mínimo: 0,42; máximo: 0,82; mediana: $0,45)$, sendo o índice inferior a 0,5 obtido por três laboratórios (Figura 2A), enquanto dois laboratórios apresentaram escores superiores a 0,7 (Figuras 2B, 2C e 2D).

A qualidade da técnica histológica teve escores médios de 1,85 (de 1,71 a 2,04; mediana: 1,7). A variação interlaboratorial quanto a este índice foi pequena, tendo todos atingido o nível de qualidade satisfatória.

A análise da imunorreatividade nuclear específica para RE, ilustrada na Figura 3, teve escore médio de 2,14 (máximo: 2,86; mínimo: 0,57; mediana: 2,14), sendo que quatro laboratórios apresentaram índice superior à média (Figuras $4 \mathrm{Ae} 4 \mathrm{~B})$, e a reatividade foi considerada insatisfatória, neste critério, em três laboratórios participantes, com escore inferior a 2 (Figuras 4C e 4D).

A presença de coloração inespecífica de fundo teve escore médio de 0,32 (de 0,19 a 0,6; mediana: 0,28), sendo que dois laboratórios obtiveram índice superior à média, mas todos obtiveram índices considerados satisfatórios.

A análise do critério técnica histológica obteve escore médio de 2,18 (de 1,72 a 2,46; mediana: 2,4), em que três laboratórios apresentaram índices inferiores à média, porém todos foram considerados satisfatórios, com escores maiores que 1,7 .

\section{Discussão}

A busca do incremento e da garantia de qualidade em medicina laboratorial tomou grande impulso na última década, criando-se, recentemente, programas de qualidade 
Principais parâmetros e resultados dos protocolos de imuno-histoquímica utilizados para Tabela 1 citoceratinas conforme o laboratório

\begin{tabular}{|c|c|c|c|c|c|c|c|c|}
\hline Laboratório & $\begin{array}{l}\text { Ac } 1^{\mathrm{a}} \\
\text { clones }\end{array}$ & Diluição & $\begin{array}{c}\text { Tempo/ } \\
\text { temperatura } \\
\text { de incubação }\end{array}$ & Amplificação & Cromógeno & $\begin{array}{c}\text { Recu- } \\
\text { peração }\end{array}$ & $\begin{array}{l}\text { Escore de } \\
\text { coloração } \\
\text { específica }\end{array}$ & $\begin{array}{l}\text { Escore de } \\
\text { coloração } \\
\text { de fundo }\end{array}$ \\
\hline 3 & AE1/AE3 & $1: 1.000$ & $18 \mathrm{~h}-4^{\circ} \mathrm{C}$ & StreptABC & $\mathrm{DAB}$ & PP & 3,37 & 0,48 \\
\hline 4 & AE1/AE3 & $1: 100$ & $18 \mathrm{~h}-4^{\circ} \mathrm{C}$ & StreptABC & $\mathrm{DAB}$ & PP & 2,53 & 0,42 \\
\hline 5 & AE1/AE3 & $1: 500$ & $18 \mathrm{~h}-2^{\circ} \mathrm{C}$ & ABC elite & $\mathrm{DAB}$ & $\mathrm{DE}$ & 2,44 & 0,58 \\
\hline 7 & AE1/AE3 & $1: 100$ & $18 \mathrm{~h}-4^{\circ} \mathrm{C}$ & StreptABC & DAB & MO & 2,92 & 0,82 \\
\hline 8 & AE1/AE3 & $1: 800$ & $18 \mathrm{~h}-4 / 8^{\circ} \mathrm{C}$ & StreptABC & DAB & PP & 3,06 & 0,49 \\
\hline 9 & AE1/AE3 & $1: 400$ & $18 \mathrm{~h}-4^{\circ} \mathrm{C}$ & LSAB & $\mathrm{DAB}$ & PP & 2,85 & 0,59 \\
\hline 10 & AE1/AE3 & 1:100 & $18 \mathrm{~h}-4^{\circ} \mathrm{C}$ & LSAB & $\mathrm{DAB}$ & M0 & 2,36 & 0,51 \\
\hline 11 & AE1/AE3 & $1: 200$ & $18 \mathrm{~h}-4^{\circ} \mathrm{C}$ & Sem amplificação & DAB & PP & 2,6 & 0,71 \\
\hline 12 & AE1/AE3 & $1: 30$ & $2 \mathrm{~h}-37^{\circ} \mathrm{C}$ & StreptABC & $\mathrm{DAB}$ & PV & 3,01 & 0,61 \\
\hline
\end{tabular}

$P P=$ panela de pressão; $P V=$ panela a vapor; $M O=$ microondas; $D A B=$ diaminobenzidina; $D E=$ digestão enzimática; StrepABC = complexo estreptavidina-biotina-peroxidase; $\angle S A B=$ labelled streptavidina-biotina; $A B C$ elite = complexo avidina-biotina.

Principais parâmetros e resultados dos protocolos de imuno-histoquimica utilizados para Tabela 2 a detecção de receptor de estrógeno conforme o laboratório

\begin{tabular}{|c|c|c|c|c|c|c|c|c|}
\hline Laboratório & $\begin{array}{l}\text { Ac } 1^{\mathrm{a}} \\
\text { clones }\end{array}$ & Diluição & $\begin{array}{c}\text { Tempo/ } \\
\text { temperatura } \\
\text { de incubação }\end{array}$ & Amplificação & Cromógeno & $\begin{array}{l}\text { Recu- } \\
\text { peração }\end{array}$ & $\begin{array}{l}\text { Escore de } \\
\text { coloração } \\
\text { especifica }\end{array}$ & $\begin{array}{l}\text { Escore de } \\
\text { coloração } \\
\text { de fundo }\end{array}$ \\
\hline 3 & $6 \mathrm{~F} 11$ & $1: 40$ & $18 \mathrm{~h}-4^{\circ} \mathrm{C}$ & StreptABC & $\mathrm{DAB}$ & PP & 2,53 & 0,42 \\
\hline 4 & 1D5 & $1: 1.000$ & $30 \min -37^{\circ} \mathrm{C}$ & Envision & $\mathrm{DAB}$ & PV & 0,57 & 0,23 \\
\hline 5 & 1D5 & $1: 50$ & $18 \mathrm{~h}-2^{\circ} \mathrm{C}$ & LSAB & $\mathrm{DAB}$ & PP & 1,94 & 0,26 \\
\hline 7 & 1D5 & $1: 2.000$ & $18 \mathrm{~h}-4^{\circ} \mathrm{C}$ & StreptABC & $\mathrm{DAB}$ & PV & 1,73 & 0,6 \\
\hline 8 & $6 \mathrm{~F} 11$ & $1: 50$ & $18 \mathrm{~h}-4 / 8^{\circ} \mathrm{C}$ & StreptABC & $\mathrm{DAB}$ & PP & 2,84 & 0,28 \\
\hline 10 & 1D5 & $1: 200$ & $18 \mathrm{~h}-4^{\circ} \mathrm{C}$ & LSAB & $\mathrm{DAB}$ & MO & 2,52 & 0,28 \\
\hline 14 & $6 \mathrm{~F} 11$ & $1: 50$ & $60 \min -25^{\circ} \mathrm{C}$ & StreptABC & $\mathrm{DAB}$ & PV & 2,86 & 0,19 \\
\hline
\end{tabular}

$P P=$ panela de pressão; $P V=$ panela $a$ vapor; $M O=$ microondas; $D A B=$ diaminobenzidina .

dedicados a imuno-histoquímica, com destaque para as ações promovidas, nos Estados Unidos, pelo College of American Pathologists (CAP) e pela Association of Directors of Surgical Pathology Laboratories (Adasp) e, na Europa, com os grupos de França, Alemanha, Inglaterra e Holanda, recentemente integrados ao United Kingdom National External Quality Assessment (UK-NEQAS) $(3,7,17,24,26)$.

Baseado nessas propostas, o grupo de patologistas que se reúne no Clube de IHQ, da SBP, selecionou como indicadores de qualidade dois dos antígenos mais pesquisados entre nós: as citoceratinas (indicador genérico de linhagens epiteliais e afins) e a proteína receptora de estrógeno. A estratégia do programa mostrou-se de fácil aplicação, devendo ser consolidada e aprimorada com o uso continuado.
O uso da solução de formalina foi universal, devendo, nas próximas ações, buscar-se a padronização das soluçõestampão para garantir o pH mais próximo de 7,4. O tempo de fixação dos espécimes não foi anotado neste estudo preliminar baseado em controles pré-selecionados pelos laboratórios entre suas melhores amostras, geralmente bem fixadas e fortemente positivas. Estudos anteriores demonstraram ser este tempo um fator relevante na qualidade da reação( ${ }^{(1,4)}$.

Devido ao custo, alguns autores têm, mais recentemente, discutido o real benefício do uso de lâminas controle adicionais, salientando-se, nesse sentido, a recente crítica de Chan ${ }^{(11)}$, que chega a sugerir a omissão dos controles positivos. Exemplo da contínua preocupação com os controles é o recente encontro promovido 


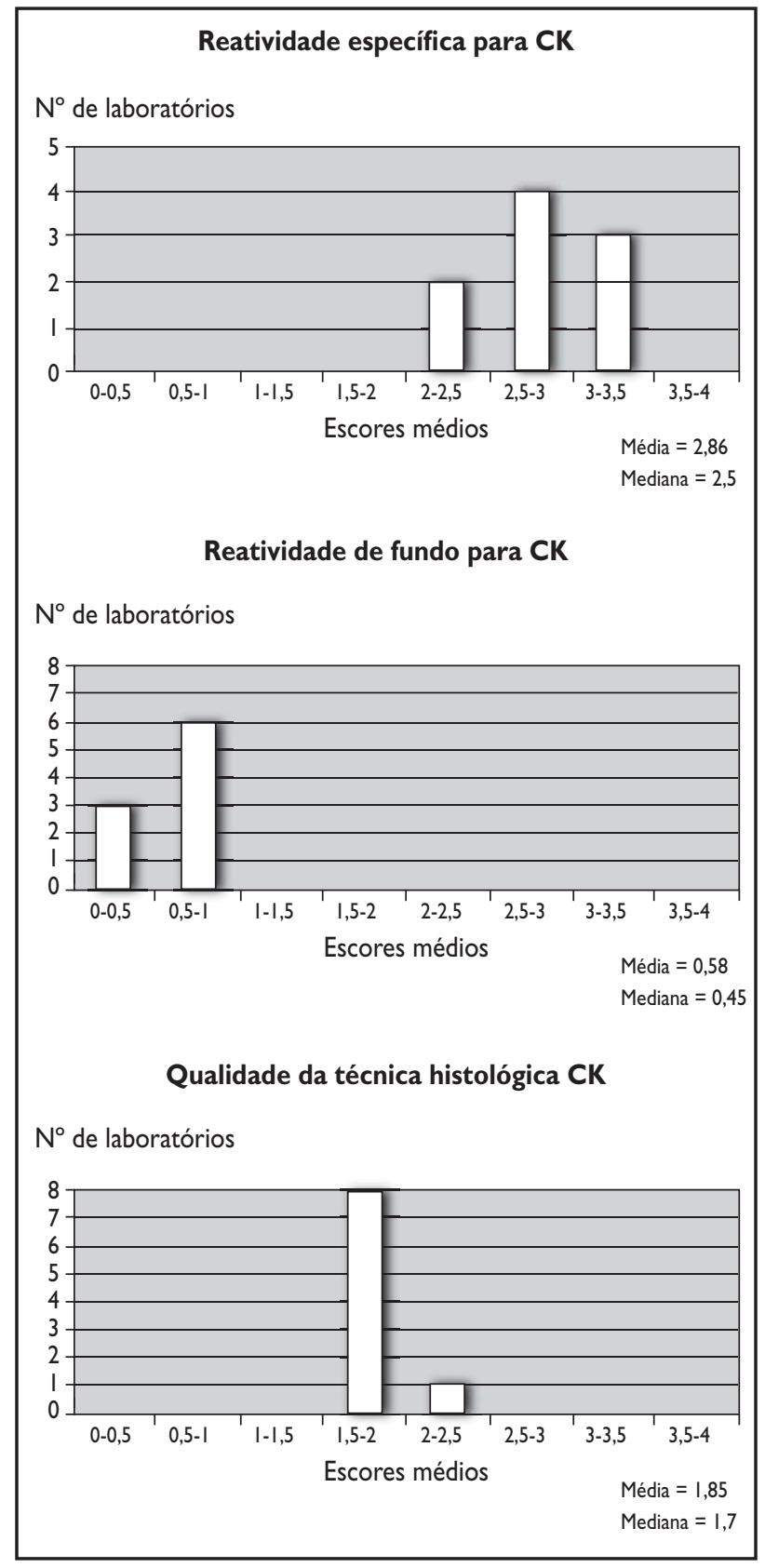

Figura 1 - Escores médios obtidos para citoceratinas (CK)

pelo Instituto Nacional de Padrões e Tecnologia (Nist) do governo norte-americano, definindo, para a detecção de HER2, que só devem ser aceitas amostras fixadas em formol tamponado $10 \%$ por lâminas controle a partir de blocos de linhagens celulares bem caracterizados, fornecendo o estudo semiquantitativo ${ }^{(14)}$. Nossa sugestão é que as amostras controle apresentem imunorreatividade moderada $(2+/ 4+)$ e que sejam submetidas a fixação similar à das amostras da rotina do laboratório. Outra utilidade essencial do uso de controles é a comparação da validade dos reagentes, motivo de recente polêmica entre nós. Os anticorpos e demais insumos em imuno-histoquímica são acompanhados por

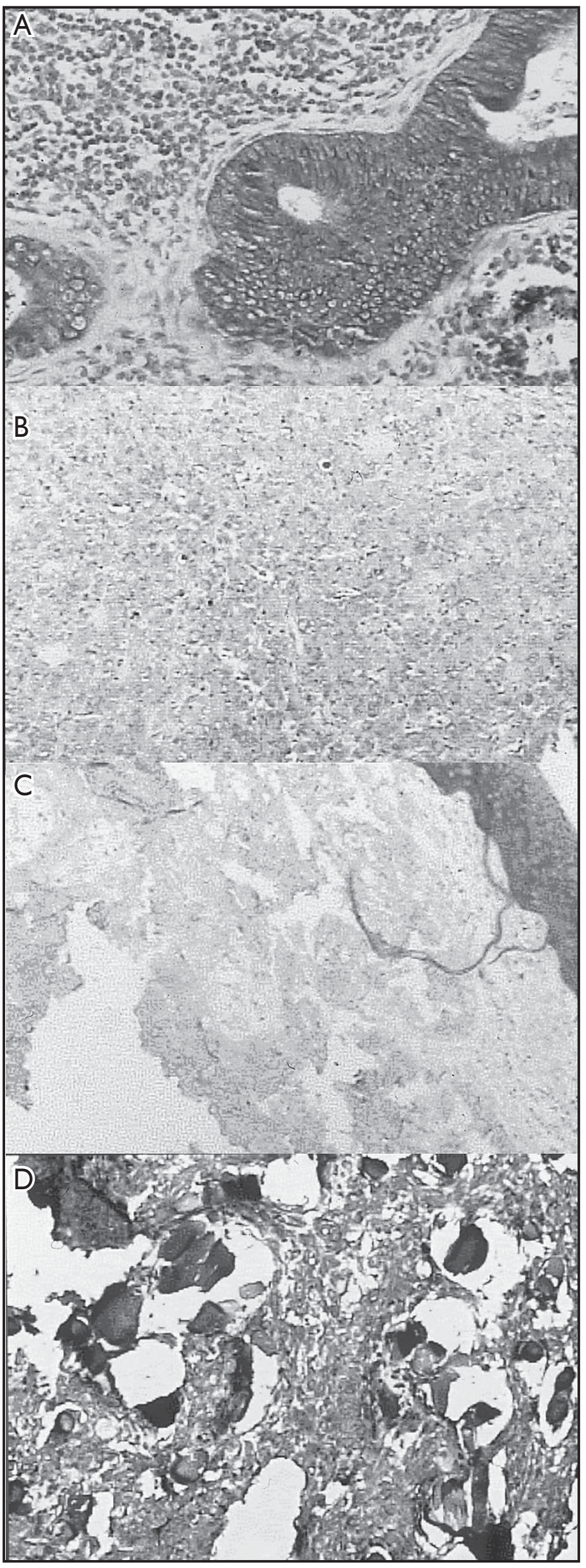

Figura 2 - Citoceratinas. A) Contraste máximo com grande intensidade da reação (i4) e ausência de fundo (f0) (3.6, AE1AE3, 200X). B) Neste campo, a intensidade de reação é baixa (i1) e a reação de fundo mostra-se evidente (f2) (8.7, AE1AE3, 100x). C) Observa-se aqui artefato histológico com descolamento e dobra das bordas atribuídos à inadequação do adesivo (4.3, AE1AE3, 100x). D) Artefato histológico de queimadura do tecido atribuída ao excesso de recuperação antigênica (7.3, AE1AE3, 100x) 


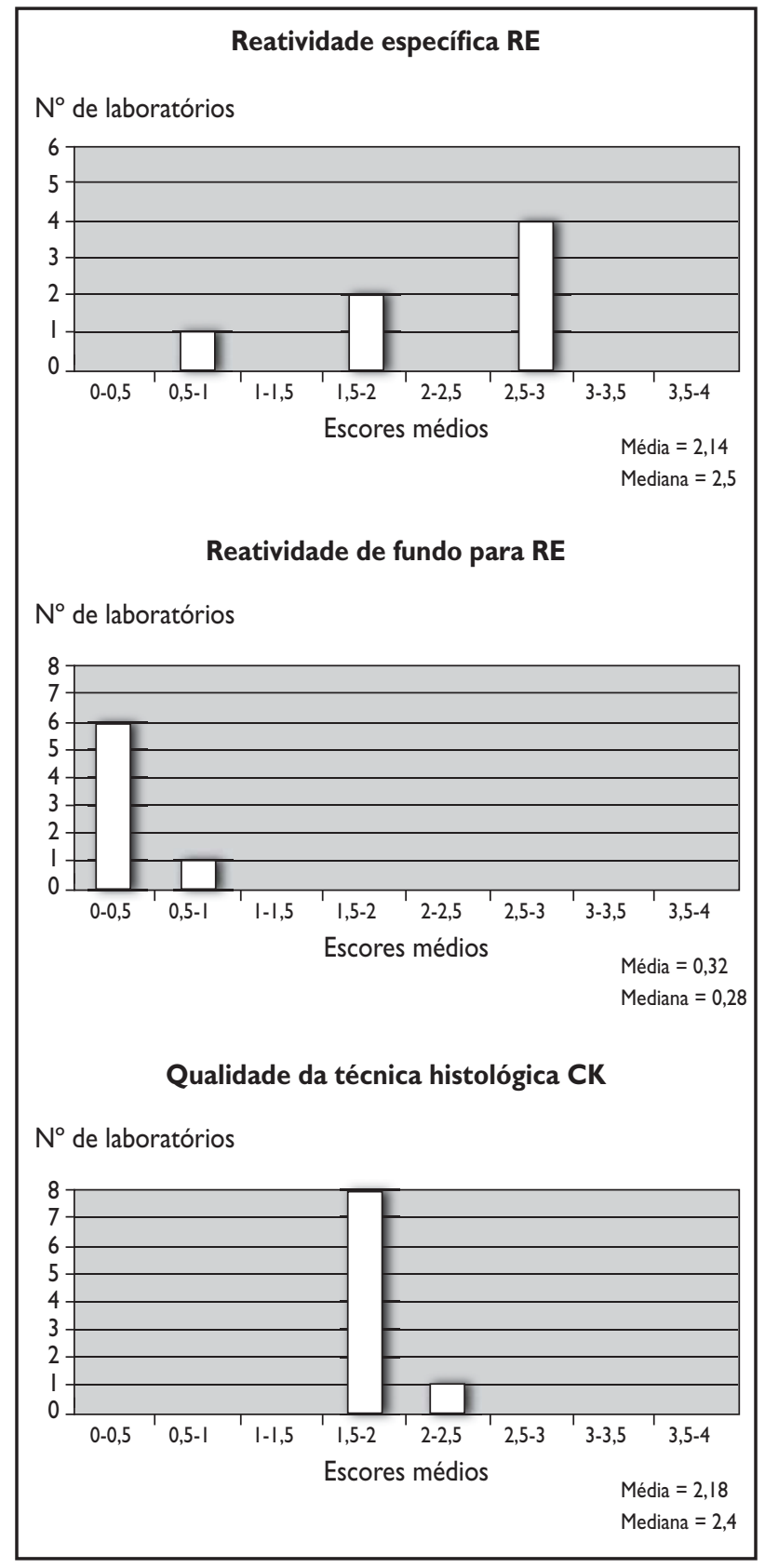

Figura 3 - Escores médios obtidos para receptor de estrógeno (RE)

folheto explicativo (bula) com a validade do reagente. Até esta data, os distribuidores assumem a responsabilidade pela vitalidade dos produtos. Os mais de 20 anos de judicioso uso da imuno-histoquímica para finalidades diagnósticas e pesquisa permitem que os especialistas do Clube de IHQ formem posição quanto ao fato de o uso dos controles de cada reação ser instrumento mais relevante para comprovação da validade dos reagentes do que a data indicada no folheto que os acompanha.

A qualidade da técnica histológica é outro item que pode ser avaliado pelo presente programa: o uso de adesivos é agora habitual e, em geral, bem efetuado

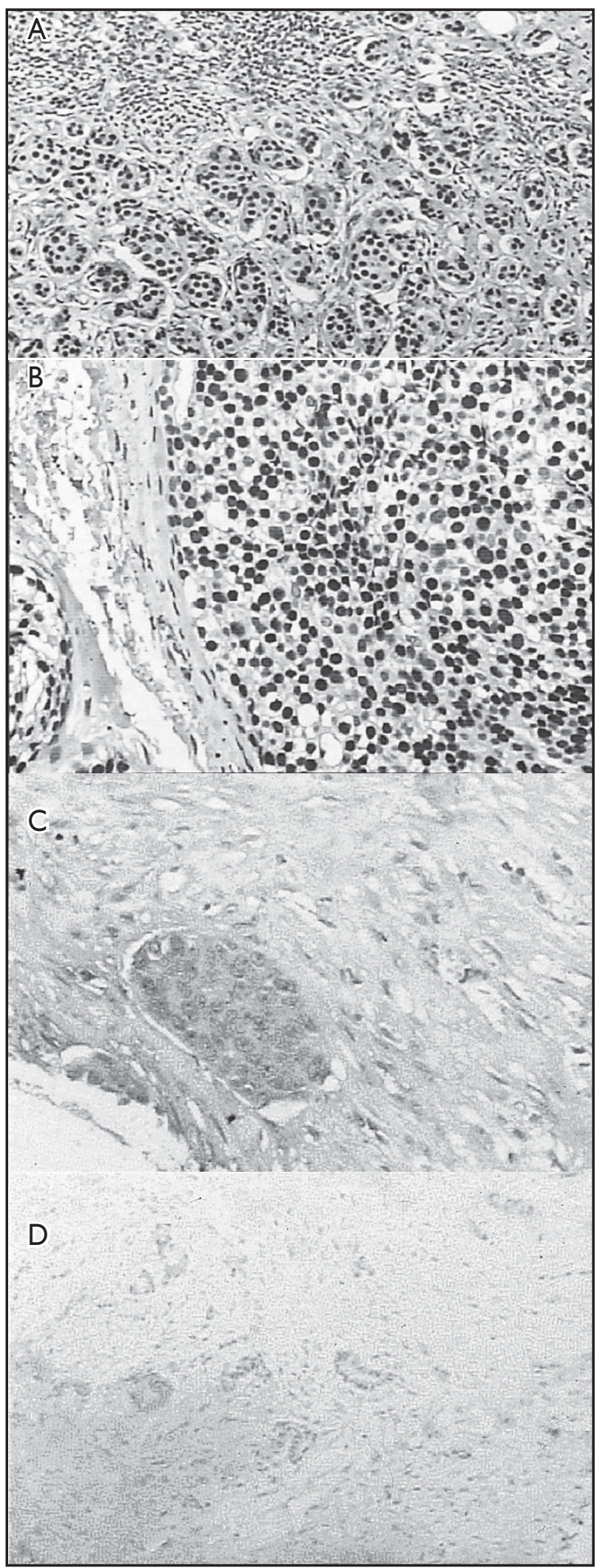

Figura 4 - Receptor de estrógeno. A) Excelente contraste, com grau de intensidade da reação (i4) e ausência de fundo (fO) $(14.18,6 F 11,100 x)$. B) A positividade nuclear é intensa nas células neoplásicas (i3) e o fundo é limpo (f0), notando-se, entretanto, separação da matriz extracelular (14.26, 6F11, 200x). C) Reatividade nuclear mínima e fundo acentuado (f3), notando-se também artefato histológico no estroma (4.14, 1D5, 200x). D) Ausência da reatividade das células neoplásicas, com fundo acentuado (f3) atribuído à deficiência no bloqueio da reação protéica (7.26, 1D5, 100x) 
entre nós, sendo grande a contribuição da adoção do organo-silano.

Cortes efetuados com navalhas descartáveis também se mostraram prática habitual nos laboratórios participantes deste projeto, permitindo secções uniformes e delgadas (preferencialmente entre 3 e 5 micrômetros), quesito essencial para as reações imuno-histoquímicas, adicionando, também, qualidade ao estudo histopatológico pelas colorações convencionais.

A questão da recuperação antigênica é essencial quando se utiliza fixação aditiva, como a efetuada por aldeídos do grupo do formol. A introdução dos métodos de recuperação pelo calor, na última década, permitiu a detecção de epitopos antigênicos anteriormente não-identificáveis, como, por exemplo, as proteínas receptoras de estrógeno ${ }^{(23,29)}$. O presente estudo expõe alguns aspectos fundamentais: assim como ocorre internacionalmente, os laboratórios brasileiros adotaram a recuperação antigênica pelo calor em suas três principais variações - forno de microondas, que apresenta diversos modelos com potência e temperatura diferentes; panela a vapor, com reação mais suave e prolongada; e panela de pressão, o método mais vigoroso de recuperação antigênica, mas que pode acarretar artefatos morfológicos, principalmente por queimadura ou destacamento de fragmentos de tecidos, como o adiposo.

O cuidadoso controle dos métodos de recuperação antigênica poderá, também, reduzir as reações inespecíficas de fundo aqui relatadas, inclusive aquelas devidas à biotina endógena, mais exuberantes nos casos submetidos às recuperações mais vigorosas.

Outro aspecto essencial é que alguns epitopos antigênicos, como as citoceratinas, são, ainda hoje, mais bem expostos pelo uso de digestão proteolítica enzimática, técnica química com diversas variáveis, desde a enzima selecionada (tripsina, pepsina, proteinase $\mathrm{K}$, pronase, etc.) até concentrações, temperatura, pH, tempo de incubação, etc. ${ }^{(8,16)}$.

Um dos laboratórios relatou o uso de tripsina para a detecção de citoceratinas e obteve razoável coloração específica, com escore médio de 2,44 e com índice de coloração de fundo igual à média $(0,58)$.

A seleção do anticorpo primário também é de grande importância: anticorpos poli ou monoclonais, com afinidades variáveis contra epitopos mais ou menos expostos em cada condição, podem acarretar resultados consideravelmente variáveis. No presente estudo, a detecção de citoceratinas foi sempre efetuada com a solução de anticorpos $A E 1+A E 3^{(12)}$, reconhecida como de grande eficácia. Entretanto alguns estudiosos, reconhecendo a menor afinidade desta solução pela citoceratina ${ }^{(8)}$, adicionaram outros anticorpos como CAM 5.2 $2^{(17)}$ ou $35 \mathrm{BH} 11^{(13)}$ no preparo doméstico de um marcador genérico de epitélios ${ }^{(9)}$.

Nos laboratórios participantes do presente estudo, a detecção de proteína receptora de estrógeno foi efetuada com os dois anticorpos atualmente considerados mais eficazes contra esta proteína, reconhecendo, entretanto, epitopos diferentes ${ }^{(10)}$.

As dificuldades de padronização em imuno-histoquímica ficam, aqui, uma vez mais destacadas na grande variação de diluições dos anticorpos primários nos diversos laboratórios. A partir dos mesmos clones, diversas indústrias produzem as soluções AE1+AE3, 1D5 e 6F11, atualmente comercializadas, sendo que os próprios laboratórios usam tempo e temperatura de incubação bastante heterogêneos, requerendo, portanto, diferentes concentrações para a obtenção de reatividade adequada.

No presente estudo, enquanto a revelação pela diaminobenzidina foi unânime, a amplificação da reação foi uma etapa relativamente homogênea: no experimento de detecção de citoceratinas, todos os laboratórios usaram o princípio da interação da vitamina biotina com as glicoproteínas avidina ou estreptavidina ${ }^{(15)}$.

O mesmo ocorreu na detecção do receptor de estrógeno, com exceção de um laboratório que, visando à eliminação da biotina endógena, usou o sistema Envision, baseado na incubação com um polímero de dextrana contendo moléculas do anticorpo secundário e da peroxidase $^{(30)}$.

Nesta área, algumas tendências predominam: as principais distribuidoras priorizam a oferta de sistemas de amplificação pré-fabricados, reduzindo as ocasiões de erro intralaboratorial e proporcionando considerável uniformização, mas, em várias situações, a um custo indesejável; de outra parte, novos métodos de amplificação têm sido desenvolvidos, sendo que alguns destes, como o sistema de amplificação por catalisação(22), têm se mostrado úteis em pesquisas visando à detecção de epitopos presentes em pequenas quantidades, enquanto outros, como o sistema Epos/Envision, como vimos aqui, já passaram a ser considerados para uso na rotina laboratorial.

Em síntese, a avaliação interlaboratorial aqui apresentada mostrou-se factível, podendo ser utilizada para levantar críticas e sugestões aos participantes, mesmo se considerada 
toda a subjetividade inerente a um processo avaliador. Essas críticas e sugestões podem levar ao incremento da qualidade dos laboratórios que se submetem ao teste.

Houve variações na detecção dos marcadores para citoceratinas e receptor de estrógeno, porém os resultados obtidos nestes quesitos pelos laboratórios participantes podem ser classificados como consistentes e plenamente aceitáveis.

A identificação de procedimentos potencialmente associados à redução de fundo permite sua correção, com o ganho continuado de qualidade nos laboratórios participantes deste tipo de programa de qualidade.

\section{Referências}

I.ALVES,V.A. F. et al.A importância da fixação em imunoisto-química: a distribuição de vimentina e citoceratinas em amostras fixadas em álcool e formol. Rev Hosp Clín Fac Med S Paulo, v. 7, p. 27-9, 1992.

2. ALVES, V. A. F. Garantia de qualidade em imuno-histoquímica. In: ALVES, V. A. F;; BACCHI C. E.; VASSALLO, J. Manual de Imuno-histoquímica da Sociedade Brasileira de Patologia, 1999, cap. I, p. I-9.

3. AUDOUIN, J. et al. Évaluation externe de la qualité technique en immunohistochimie: resultats d'une étude préliminaire multicentrique. Ann Pathol, v. 2, p. 129-33, 1997.

4. AZUMI, N.; BATTIFORA, H. The distribution of vimentin and keratin in epithelial and nonepithelial neoplasms: a comprehensive immunohistochemical study on formalin and alcool-fixed tumors. Am / Clin Pathol, v. 88, p. 286, 1987.

5. BACCHI, C. E. Caracterização de sítios primários de carcinomas metastáticos. In: ALVES, V. A. F. et al. Manual de Imunohistoquímica da Sociedade Brasileira de Patologia, 1999, cap. 3, p. 23-9.

6. BALATTON, A. J. et al. Optimization of heat-induced epitope retrieval for estrogen receptor determination by immunohistochemistry on paraffin sections: results of a multicentric comparative study. Appl Imunohistochem, v. 4, p. 259-63, 1996.

7. BALATTON, A. J. et al. Recommandations pour l'évaluation immunohistochimique des récepteurs hormonaux sur coupes en paraffine dans les carcinomes mammaries. Ann Pathol, v. 16, p. I44-8, 1996.

8. BATTIFORA, H.; KOPINSKI, M.The influence of protease digestion and duration of fixation on the immunostaining of keratins. A comparison of formalin and ethanol fixation. J Histochem Cytochem, v. 34, p. 1095-100, 1986.

9. BATTIFORA, H. Diagnostic uses of antibodies to keratins. A review and immunohistochemical comparison of seven monoclonal and three polyclonal antibodies. In: FENOGLIO, C.; WOLFF, M. Progress in surgical pathology. Philadelphia: Field and Wood, v. 8, 1987.

I0. BEVITT, D. J. et al. New monoclonal antibodies to oestrogen and progesterone receptors effetive for paraffin section immunohistochemistry.J Pathol, v. I83, p. 228-32, 1997.

I I. CHAN, J. K. Advances in immunohistochemistry: impact on surgical pathology practice. Semin Diagn Pathol, v. 17 , p. 170-7, aug. 2000.

12. COOPER, D. et al. Classification of human epithelia and their neoplasms using monoclonal antibodies to keratins strategies applications and limitations. Lab Invest, v. 52, p. 243-56, 1985

13. GOWN, A. M.; VOGEL, A. M. Monoclonal antibodies to intermediate filament proteins of human cells: I. Unique and cross-reacting antibodies. J Cell Biol, v. 95, p. 4I4, 1982.

I4. HAMMOND, M. E. H. et al. Standard reference material for HER2 testing: report of a National Institute of Standards and Tecnology. Sponsored Consensus Workshop. Appl Immun. Mol Morph, v. II, p. I03-6, 2003.

15. HSU, S. M. et al.The use of antiavidin antibody and avidin-biotinperoxidase complex in immunoperoxidase techniques. Am J Clin Pathol, v. 75, p. 816-21, 1981.

16. HUANG, S. et al. Application of immunofluorescent staining in paraffin sections improved by trypsin digestion. Lab Invest, v. 35, p. 383-91, 1976.

17. JENSEN, M. L. et al. Imunohistochemistry in tumor diagnosis: external quality assessment of I 3 departments of pathology in Western Denmark. Appl Imunohistochem, v. 5, p. 35-44, 1997.

18. MAKIN, C.A. et al. Monoclonal antibody to cytokeratin for use in routine histopathology. J Clin Pathol, v. 37, p. 975, 1984.

19. MAXWELL, P.; MC CLUGGAGE, W. G. Audit and internal quality control in immunohistochemistry. J Clin Pathol, v. 53, p. 929-32, 2000

20. MELLO, E. S.;ALVES,V.A. F. Glossário dos principais marcadores imunoistoquímicos. In: ALVES, V. A. F.; BACCHI, C. E.; VASSALLO, J. Manual de Imuno-histoquímica da Sociedade Brasileira de Patologia, 1999, cap. 22, p. 260-70.

21. MENGEL, M. et al. Inter-laboratory and inter-observer reproducibility of immunohistochemical assessment of the ki-67 labelling index in a large multi-centre trial. J Pathol, v. 198, p. 292-9, 2002.

22. MOKRY, J. Versatility of immunohistochemical reactions: comprehensive survey of detection systems. Acta Medica, v. 39, p. 129-40, 1996.

23. NORTON, A. J. et al. Brief, high temperature heat denaturation (pressure cooking): a simple and effective method of antigen retrieval for routinely processed tissues. J Pathol, v. 173, p. 37I-9, 1994.

24. RHODES, A. et al. Reliability of immunohistochemical demonstration of oestrogen receptors in routine practice: interlaboratory variance in the sensitivity of detection and evaluation of scoring systems. J Clin Pathol, v. 53, p. 125-30, 2000.

25. RHODES A., et al. Immunohistochemical demonstration of oestrogen and progesterone receptors: correlation 
of standards achieved on in house tumours with that achieved on external quality assessment material in over I 50 laboratories from 26 countries. J Clin Pathol, v. 53, p. 292-301, 2000.

26. RÜDIGER, T. et al. Quality assurance in immunohistochemistry: results of an interlaboratory trial involving 172 pathologists. Am J Surg Pathol, v. 26, p. 873-82, 2002.

27. SCHMITT, F. C. Marcadores prognósticos em carcinoma mamário. In: ALVES, V. A. F.; BACCHI, C. E.; VASSALLO, J. Manual de Imuno-histoquímica da Sociedade Brasileira de Patologia, 1999, cap. 4, p. $30-46$.
28. SCHMITT, S. J. Pharmacopathology: a new spin on an old idea. Am J Surg Pathol, v. 27, p. I21-3, 2003.

29.SHI,S.R. et al.Antigen retrieval in formalin-fixed, paraffin embedded tissues: an enhancement method for immunohistochemical staining based upon microwave oven heating of tissue sections. J Histochem Cytochem, v. 39, p. 741-8, 1991.

30.VAN DER LOOS, C. M. et al. The use of enhanced polymer onestep staining reagents for immunoenzyme double-labelling. Histochem J, v. 28, p. 709-14, 1996.

3I.VAN DIEST, P. J. et al. A scoring system for imunohistochemical staining: consensus report of the task force for basic research of the EORTC-GCCG.J Clin Pathol, v. 50, p. 80I-4, 1997. 